\title{
Factors Affecting Techniques of Teaching Theorem Proof
}

\author{
Nina Tarasenkova ${ }^{1, *}$, Iryna Akulenko ${ }^{2}$, Mykhailo Burda ${ }^{3}$, Kira Hnezdilova ${ }^{4}$ \\ ${ }^{1}$ Department of Mathematics and Methods of Teaching Mathematics, Educational-Scientific Institute of Informational and \\ Educational Technologies, Bohdan Khmelnytsky National University of Cherkasy, Ukraine \\ ${ }^{2}$ Department of Algebra and Calculus, Educational-Scientific Institute of Informational and Educational Technologies, Bohdan \\ Khmelnytsky National University of Cherkasy, Ukraine \\ ${ }^{3}$ Department of Mathematical and Computer Education, The Institute of Pedagogy of the National Academy of Pedagogical Sciences \\ of Ukraine, Ukraine \\ ${ }^{4}$ Department of Pre-school Education, Educational-Scientific Institute of Pedagogical Education, Social work and Arts, \\ Bohdan Khmelnytsky National University of Cherkasy, Ukraine
}

Received November 26, 2019; Revised December 23, 2019; Accepted January 16, 2020

Copyright $\bigcirc 2020$ by authors, all rights reserved. Authors agree that this article remains permanently open access under the terms of the Creative Commons Attribution License 4.0 International License

\begin{abstract}
Students' mastering the art of proof is one of the most important educational results of teaching Mathematics in the secondary school. The study shows that there are significant challenges, gaps, and weaknesses in the practice of teaching reasoning and proving. The goal of the research is to determine the way of using traditional teaching practices to present reasoning and proving, the way of organizing the review and mastery of the theorem proofs. In addition, the obvious and hidden factors affecting the students' productivity in these activities were identified. To study the problem, a survey that involved 136 Mathematics teachers across Ukraine was carried out. A standard close-ended questionnaire was developed. Factor analysis was used to analyze the results of the survey. The important factors determining the time efficiency when a teacher organizes teaching and learning of a theorem proof, were discovered. The analysis of the factors and numerical loadings of variables forming them, result in the conclusions presented in this paper.
\end{abstract}

Keywords Secondary School, Teaching Mathematics, Theorem, Teaching Theorem Proof

\section{Introduction}

Traditionally, teaching and learning Mathematics is associated with not only mastering the system of knowledge regarding the quantitative characteristics of environment objects but also the ability to find the numerical values of these characteristics. Equally significant results are the mastered skills of students to think logically and consistently, to find relevant arguments, not to break the logical motivation in the conclusions. These students' skills are formed, particularly, while proving mathematical statements. Schoolchildren should understand that generalizations based on observations, case studies, and finding analogies require argumentative proof. "Deductive mathematical proof offers human beings the purest form of distinguishing right from wrong; it seems so transparently straightforward - yet it is surprisingly difficult for students" (D. L. Ball, C. Hoyles, H. N. Jahnke, \& N. Movshovitz-Hadar [1, p. 5]). In the proof of mathematical statements, favorable conditions are created to activate students' educational abilities and cognitive mental processes (attention, memory, thinking, cognitive activity, independence).

A wide range of scientific studies (D. L. Ball, C. Hoyles, H. N. Jahnke, \& N. Movshovitz-Hadar [1]; P. Van Hiele \& D. Van Hiele-Geldof [2]; D. L. Ball \& H. Bass [3]; J. Franklin \& A. Daoud [4]; H. L. Healy \& C. Hoyles [5]; R. Marrades \& A. Gutierrez [6]; and others) and the practice of teaching Mathematics indicate the need to pay particular attention to teaching students to prove mathematical statements.

Research analysis shows that the emphasis in approaches to teaching students to prove statements changes over time from mandatory formal memorizing (learning by heart) the steps of proof to providing conditions to understand the main idea of the proof. Nowadays, the main learning result is the students' ability to build independently the chains of logically consistent conclusions that are sufficiently and appropriately argumentative. The education process should provide an 
evolution of the students' understanding of mathematical proof and improve their understanding (R. Marrades \& A.Gutierrez [6]). This problem is still in the focus of scholars' and practitioners' attention.

\subsection{Background of the Study}

We pointed out and analyzed the main directions of scientific studies of the problem in the paper [7]. Our studies stated that when applying different practices to teach students theorems and their proofs, present working teachers traditionally follow the sequence:

1) motivating to learn a theorem;

2) presenting a theorem;

3) working with the wording of a theorem;

4) motivating to prove a theorem;

5) searching with students the way to prove a theorem;

6) presenting reasoning and proving;

7) reviewing and mastering the proof;

8) applying the learned proof solutions to prove other mathematical statements.

Our research $[7 ; 8 ; 9]$ concerned the first four stages. Collective researches $[10 ; 11 ; 12]$ show some approaches to the implementation of stages 4) and 5). However, the problem is rather complicated; its different aspects are considered by the scientists from around the world.

We have analyzed the works of different authors to determine the foundation for further research. A. Malek \& N. Movshovitz-Hadar [13][14] studied the effect of using a "Transparent Pseudo-Proofs" (TPP). A Transparent Proof (TP) is a proof of a particular case which is small enough to serve as a concrete example, yet large enough to be considered a non-specific representative of the flow of arguments in the proof of the general case; one can see the formal proof through it since nothing specific to the particular case enters the transparent proof (N. Movshovitz-Hadar [14[14], p.29]). To reflect the fact that a TP is not a proof (of the general case), the term was modified to 'Transparent Pseudo Proof', or 'Transparent P-Proof' (N. Movshovitz-Hadar \& A. Malek [15]).

There is a point of view that arguments from physics are very useful in searching with students the way to prove a theorem (Polya [16; 17]; G. Hanna \& N. Jahnke [18]).

A. Stylianides \& D. Ball [19] researched the impact of «two-column proof» in presenting reasoning and proving. The reasoning is structured in clear steps, with argumentation for each step in such proofs. The sequence of reasoning and their argumentation is structured as a table.

D. Solow [20], S. Senk [21], P. Van Hiele \& D. Van Hiele-Geldof [22] confirm the expediency of using Proof Map method (PMM) for searching proof. Proof maps (PM) are created to show (using a graphic) all possible consequences of a certain fact given in the theorem hypothesis or identified while reasoning (the object belonging to the concept scope, definite property in the studied object). Also, students can use PM to visualize sufficient conditions to establish a certain fact or the property of the object studied. However, PM reflects the analytical-synthetic method of proof.

G. Hanna \& N. Jahnke [23] considered mathematics proofs and their application.

Current researches (T. Shyrikova [24], R. Marrades \& A. Gutierrez [6], C. Hoyles \& R. Noss [25], M. De Villiers [26; 27], et al.) focus on the application of Dynamic Geometry Software (DGS) and computer experiments in teaching students to prove the mathematical statement.

D. Thompson [28], R. Moore [29] pointed out background for students' difficulties with constructing proofs: 1) students' inability to state definitions and to use them to structure a proof; 2) refraining from generating and using their examples; 3 ) lack of understanding of the mathematical language and limited ability to use it; 4) lack of knowledge as to how to start a proof; 5) inadequate concept images; 6) little intuitive understanding of the concepts involved.

Thus, the problem of students' reasoning mastery in a theorem proof was and remains relevant in the Mathematics education theory despite a number of researches.

\subsection{The Objectives of This Study}

Students have some difficulties studying the proof of theorems. These difficulties can be divided into two groups: 1) arising at the stage of presenting a theorem and working with the wording of the theorem $[7 ; 8] ; 2$ ) arising at the stage of proving and mastering a theorem proof. Our practice of teaching Mathematics in K9-K11 shows that students have some difficulties at all the stages regardless of a teacher's support or assistance. Another problem is students' independent proving of a theorem.

The reasons of students' difficulties may be not only the specifics of the mathematical content and the ways of reasoning in the theorem proof. It is also important how a teacher organizes teaching a theorem proof, whether he/she implements the consolidation stage of a theorem proof, what techniques of learning and cognitive activity he/she uses, what leaning means he/she uses, what hidden factors have a significant impact on the effectiveness and efficiency of this work.

The objectives of this study are:

1) to consider how traditional practices are used to teach students to present reasoning and proving;

2) to consider how do teachers organize students' reviewing and mastering the proof;

3) to identify the obvious and hidden factors that affect the students' productivity in these activities. 


\section{Materials and Methods}

\subsection{Study Design}

The study area. The research was conducted in Ukraine.

The study population. The total coverage sample included 136 mathematics teachers across Ukraine.

Sampling. The conclusion about the representativeness of the sample is made based on the analysis of the range of the oscillations of the answers to individual questions of the questionnaire. We took such a basis for the conclusion; since sampling was random, the scale of measurement of the answers to the questions was either nominal or ranked. Under these conditions, the distribution of the response range of the received sample response reflects the distribution of the response oscillations in the aggregate [6]. The overall response rates of the questionnaire differ by $\pm 5 \%$ from those obtained in our survey.

The teachers were distributed in the following way: $54.4 \%$ of teachers teach $\mathrm{K} 7 ; 56.6 \%$ of teachers teach $\mathrm{K} 8$; $52.2 \%$ teach $\mathrm{K} 9 ; 38.2 \%$ teach K $10 ; 39 \%$ teach $\mathrm{K} 11$. The term of work at school for teachers varies. $8.8 \%$ of respondents have up to 5 years of work experience; $13.2 \%$ of teachers have from 5 to 10 years of work experience; $26.5 \%$ teachers' experience ranges from 10 to 20 years; $51.5 \%$ of teachers have worked for more than 20 years. Thus, the survey was administered to efficient, experienced teachers who have an established personal teaching philosophy and have acquired substantial experience in teaching students of theorems and their proofs.

\subsection{Data Collection}

A standard closed ended questionnaire was developed to evaluate the teachers' beliefs and attitudes toward traditional practices used to teach students reasoning and proving, reviewing and mastering the proof of theorem. The data was collected within one month. Every participant filled in the questionnaire form. Each questionnaire took from 10 to 15 minutes to be filled in, there were no missing questionnaires. The purpose of the study was explained to every participant. The participants were reminded that the information should be used only for the purpose of the study. The data was analyzed manually by simple statistical method and presented in the forms of tables, graphs and figures.

Factor analysis [30] was used to process the survey results with the help of SPSS 19.0 software package. Firstly, the correlation matrix for all variables was calculated and factors were separated by using the main components analysis method. Secondly, factors were rotated to simplify the structure (Varimax rotation with Kaiser normalization was used). The factors were interpreted as integral variables.

\section{Results}

We asked teachers if they find it necessary to teach proofs at Geometry lessons at secondary school. The teachers' answers to this question are: "Yes, sometimes I teach to prove only some theorems given in the textbook" (65.4\%); "Yes, I always teach to prove all theorems given in the textbook" (24.3\%); "Never. I suggest that students use theorems as ready facts" (7.4 \%) (Figure 1). Besides, the teachers $(0.7 \%)$ point out that they teach students to prove only those theorems provided by Geometry Curriculum for secondary school. They pay particular attention to proofs in the classes with the advanced study of Mathematics $(0.7 \%)$.

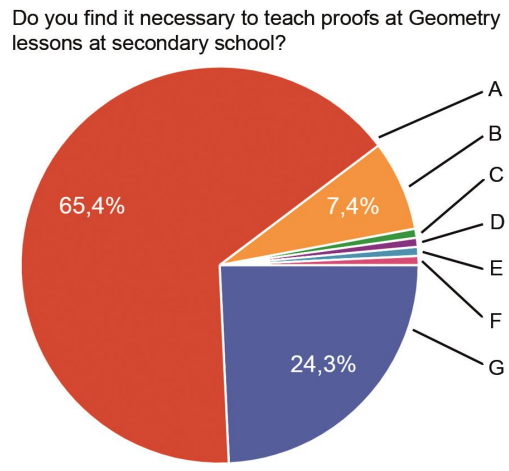

A Yes, I always teach to prove all theorems given in the textbook

B Yes, sometimes I teach to prove only some theorems given in the textbook

C Never. I suggest that students use theorems as ready facts

D We prove only those statements, which are indicated in the Curriculum

E We prove those statements that can be proved not in an algebraic way F Proofs are considered only with students who are learning Mathematics in depth

G We consider the proof only of key theorems

Figure 1. Answers to the question 1

$$
\begin{aligned}
& \text { How do you organize teaching the proofs } \\
& \text { of the geometry course theorems? }
\end{aligned}
$$

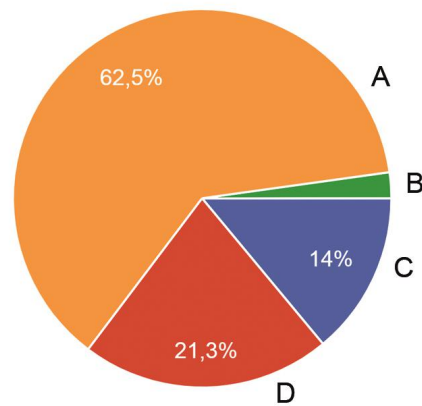

A I try to consider the proofs of all the theorems;

B I try to consider the proofs of some theorems in the classroom and do not consider other ones at all;

C I consider the proofs for some theorems in the classroom and offers students to learn other theorems independently at home;

D I do not consider it necessary to spend any time proving the obvious facts.

Figure 2. Answers to the question 2 
The survey shows that the overwhelming majority of teachers $(62.5 \%)$ prefers to consider the proofs for some theorems in the classroom and offers students to learn other theorems independently at home (Figure 2). Approximately the same number of respondents tries to consider the proofs of all theorems (14\%) or the proofs of some theorems in the classroom and do not consider other ones at all $(21.3 \%)$.

$2.2 \%$ of survey participants do not consider it necessary to spend time proving the obvious facts (such results are within the error of the study).

An additional focus of the research is to determine the dominant way of teacher's collaboration with students on theorem proof in educational practice, to find general methodological schemes used by the teachers in teaching students to prove theorems, to determine the ways to master the way of proving the theorems, to find difficulties that students have at these stages of proving the theorem. The most used ways of teacher's collaboration with students on theorem proof among the participants of the survey prove to be the following ones (Figure 3):

1) I offer an idea or plan of the proof to the students, and they subsequently implement it independently (perhaps, with the support of a teacher) (47.1\%);

2) I divide the work with a theorem into the chain of related problems (isolation of the hypothesis and the conclusion of the theorem; the isolation of elements satisfying the hypothesis of the theorem, on the ready-made drawings; making the drawing that would simulate the hypothesis of the theorem; finding the necessary and sufficient conditions for designing the chains of inferences proving the theorem) that are solved by students under the guidance of the teacher (41.9\%);

3) I divide the work with a theorem into the chain of subproblems, each of which takes a separate step in the proof and which are solved by the students in collaboration with the teacher (38.2\%);

4) I offer the ready-made proofs for the students to write down in the copy-books, to consider and reproduce (30.1\%);

5) I offer students heuristic instructions and the list of properties of the main notions for relevant use in the proof; the further proof is performed by the students independently (24.3\%);

6) I divide the work with a theorem into the chain of interrelated problems (isolation of the hypothesis and conclusion of the theorem; the isolation of elements satisfying the condition of the theorem, on the ready-made drawings; making the drawing that would simulate the condition and requirement of the theorem; finding the necessary and sufficient conditions for designing the chains of inferences proving the theorem), that are solved by students

\section{independently with further control of the teacher} $(11.8 \%)$;

7) I divide the work with a theorem into the chain of subproblems, each of which implements a separate step in the proof and which are solved by the students independently (11\%).

The analysis of the survey participants' responses shows that the vast majority of teachers prefer students' work with the support or under the guidance of a teacher in the process of proving a theorem; fewer respondents pay attention to students' independent work.

\section{How do you organize collaboration with students on theorem proof in educational practice?}

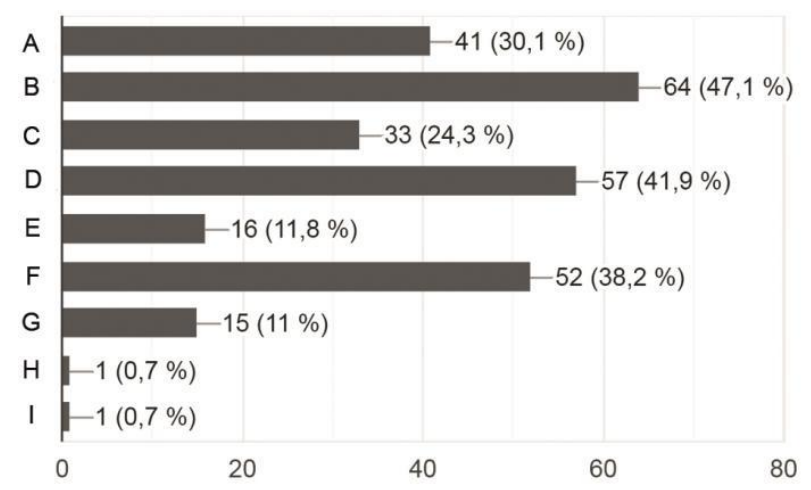

A I offer the ready-made proofs for the students to write down in the copy-books, to consider and reproduce;

B I offer an idea or plan of the proof to the students, and they subsequently implement it independently (perhaps, with the support of a teacher);

C I offer students heuristic instructions and the list of properties of the main notions for relevant use in the proof; further proof is performed by the students independently;

D I divide the work with a theorem into the chain of related problems that are solved by students under the guidance of the teacher;

E I divide the work with a theorem into the chain of interrelated problems that are solved by students independently with further control of the teacher;

F I divide the work with a theorem into the chain of subproblems, each of which takes a separate step in the proof and which are solved by the students in collaboration with the teacher;

G I divide the work with a theorem into the chain of subproblems, each of which implements a separate step in the proof and which are solved by the students independently;

H It depends upon obstacles;

I It depends upon obstacles.

Figure 3. Answers to the question 3

To provide different methods of proving a theorem (analytical, synthetic, analytic-synthetic), students must be able to establish the type of logical connections between two statements. There are three types of logical connections between two statements (a consequence with necessity follows the foundation, a definite foundation is sufficient to establish a definite consequence). We study whether teachers organize the work with their students to establish theses connection types in the chains of reasoning in the ready-made or "invented" proof of a theorem. The survey shows (Figure 4) that such kind of 
work is performed by $22.8 \%$ of respondents. Most respondents $(66.2 \%)$ pay insufficient attention to it and do it episodically; $11 \%$ of the respondents do not do it at all. Therefore, students' difficulties in constructing logical chains of reasoning that were identified in the subsequent study are quite reasonable.
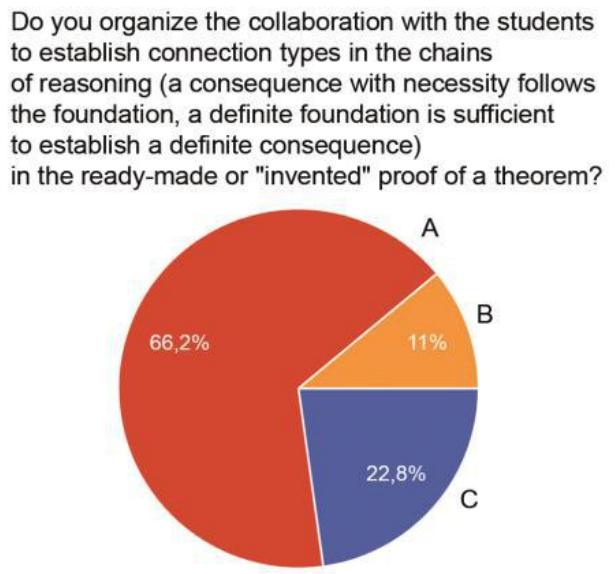

A Yes, I always organize such work with the students;

B No, I do not organize such work with the students at all;

C Yes, I sometimes organize such work with the students.

Figure 4. Answers to the question 4

\section{What type of techniques do you prefer while looking} over and mastering the method of theorem-proof?

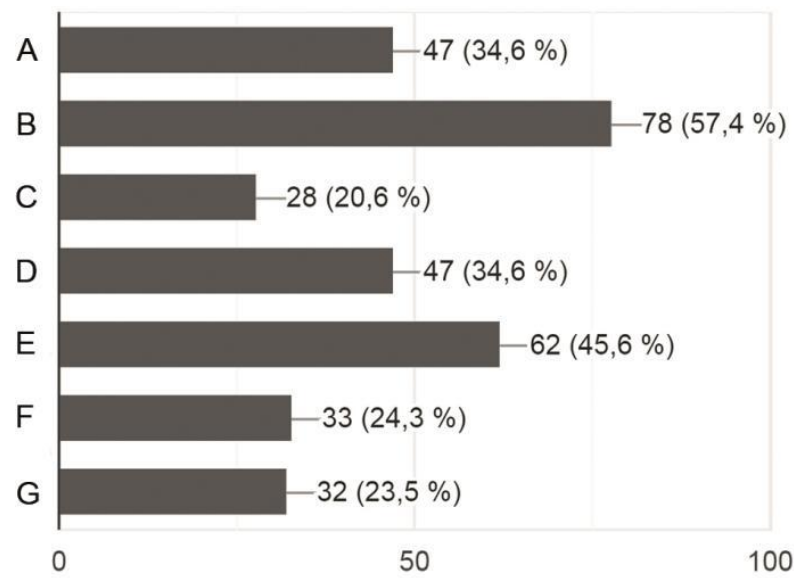

A The method when the teacher's explanation and work with illustrations in a textbook are decisive;

B Heuristic conversation;

C Problem-based methods in the modification when problem statements or problem questions are put by a teacher, and the solving problem is done by students;

D The research-based method;

E All methods mentioned above.

Figure 5. Answers to the question 5

The study aims at determining the educational methods, and means used by teachers in the practice of teaching students to prove the theorems. The predictable results prove (Figure 5) to be the fact that in teaching students to prove theorems, teachers (65.4\%) use problem-based methods in the modification when problem statements or problem questions are put by a teacher, and the solving problem is done by students. Most teachers $(61 \%)$ use the method when the teacher's explanation and work with illustrations in a textbook are decisive. 56.6\% of survey participants prefer heuristic conversation. $26.5 \%$ of respondents teach students the proofs of theorems, involving the research-based method when the teacher creates the conditions for students to independently set the purpose of the study (using construction, measurements, observations, etc.), to carry out their research, to present the results. Thus, it can be concluded that the potential of the research-based method is not used sufficiently in teaching students of theorem proofs.

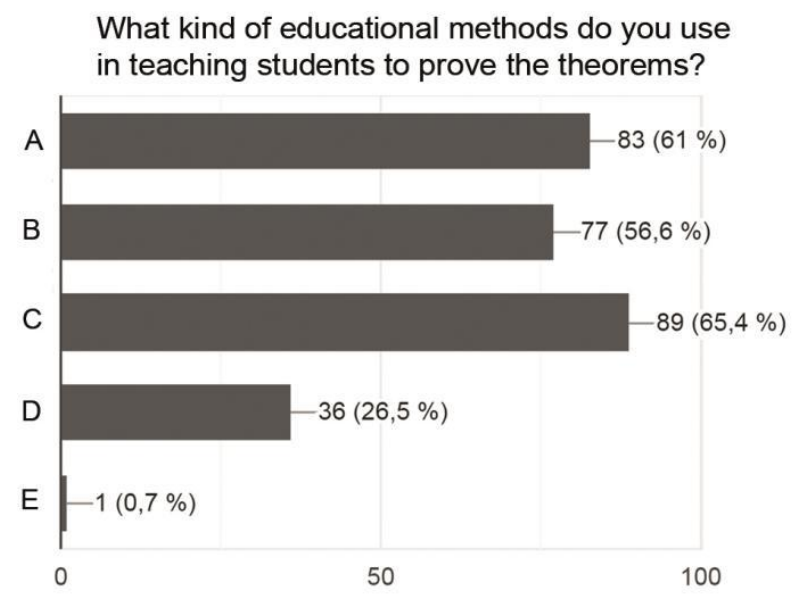

A The textbook;

B Multimedia presentations;

C Handout visual material;

D Electronic posters;

E Systems of dynamic geometry;

F Blackboard and chalk;

G Set of tables.

Figure 6. Answers to the question 6

Education means for teaching proofs are a significant component of the educational environment having a significant impact on the effectiveness of teaching and learning proofs techniques. The survey reveals (Figure 6) that the textbook itself plays a leading role. $80.9 \%$ of respondents prefer it. In addition to the textbook, the interviewed teachers refer to multimedia presentations (66.2\%), handout visual material $(44.9 \%)$, electronic posters $(8.8 \%)$, and systems of dynamic geometry $(16.9 \%)$.

The study also aims at determining how often and what type of difficulties students have while proving a theorem. The survey shows that $98.5 \%$ of teachers fix frequently occurring difficulties in the students' proofs of theorems.

The most common difficulty (Figure 7), according to 
$64 \%$ of the interviewed teachers, is the inability of students to organize a logical chain of reasoning in the proof. $39.7 \%$ of respondents point out, that students do not see the need for proof at all. $29.4 \%$ of recipients point out schoolchildren's inability to give appropriate argumentation of some steps in the proof. $24.3 \%$ of respondents stress that students cannot give possible consequences from certain foundations (using the properties of the concepts involved in the proof); $14.7 \%$ of the survey participants indicate the students' inability to give appropriate arguments to some conclusions in the proof.

$24.3 \%$ of the survey participants stress that students have some difficulties on the stage of analyzing the wording of the theorem; they cannot distinguish what is given and what should be proved. $22.1 \%$ of teachers point out that students do not differentiate the properties of the concepts used in the proof of a theorem and their features. A significant part of the survey participants $(22.8 \%)$ stresses that it is difficult for students to distinguish the main idea in the proof. $14 \%$ of the participants point out the students' inability to make up a plan of the proof. The obtained data show a lot of difficulties in teaching students to prove a theorem and the necessity to improve this work.

\section{What type of difficulties students have while performing the theorem-proof?}

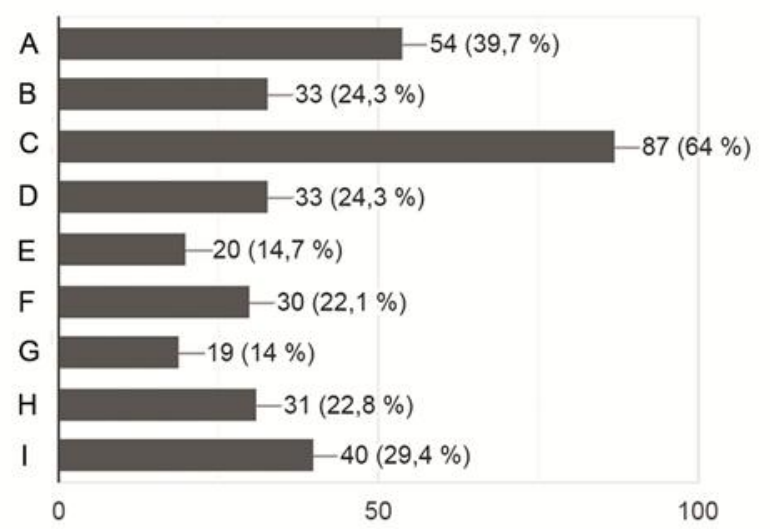

A Students do not see the need for proof at all;

B Students have some difficulties in analyzing the wording of the theorem;

C Students are unable to organize a logical chain of reasoning;

D Students cannot give possible consequences from definite foundations (using the properties of the concepts attracted to the proof);

E Students cannot give appropriate argumentation of some conclusions;

F Students do not differentiate the properties of the concepts used in the theorem-proof and their features;

G Students cannot make up a plan of the proof;

H Students cannot distinguish the main idea in the proof;

I Students cannot give appropriate argumentation of some steps in the proof.
To counterbalance the above-mentioned difficulties of students in practicing the proof of a theorem, a teacher should pay additional attention to reviewing and mastering the method of proving a theorem. This stage of work with the proof of a theorem is rather important. At the same time, the survey shows (Figure 8) that the stage of reviewing and mastering the method of proving a theorem is implemented unsystematically by $50.7 \%$ of the survey participants; and $18.4 \%$ of teachers neglect this kind of work (for various reasons: no time, no need, etc.). $29.4 \%$ of the respondents pay due attention to the work of mastering the method of proving a theorem.

\section{Do you organize students' looking over and mastering the method of theorem-proof?}

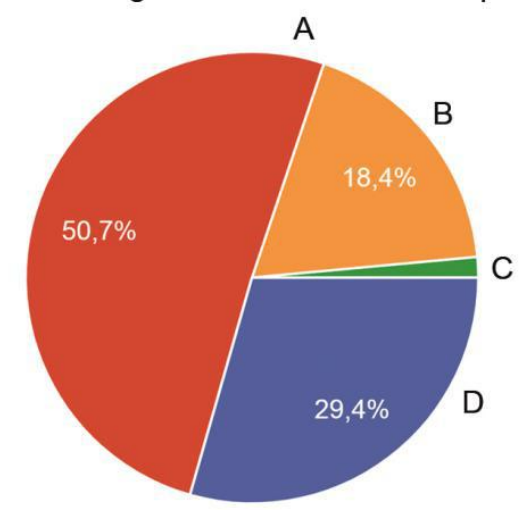

A Yes, I sometimes organize such work with the students;

B No, I do not organize such work with the students at all because of lack of time;

C No, I do not organize such work with the students at all because of no need;

D Yes, I always organize such work with the students.

Figure 8. Answers to the question 8

The survey aims at additional identifying the techniques teachers prefer while reviewing and mastering the method of proving a theorem. The survey results show (Figure 9) that teachers prefer the following techniques: to offer students to distinguish the main idea or plan of the proof $(57.4 \%)$; to offer students to give the list of the main notions, axioms, previously proved theorem used in this theorem proof $(45.6 \%)$; to offer students to reproduce (orally or in pen) the proof of a theorem (34.6\%); to offer students to fill in the gaps in the given variant of the theorem proof where argumentation or some steps of the proof are missed (34.6\%); to offer students to comment some drawings that demonstrate every step in the proof of a theorem separately and to make appropriate conclusions (24.3\%); to offer students to supplement the drawing to make the stages of the theorem proof clear $(23.5 \%)$; to offer students give an argument to each stage of the proof (20.6\%).

Figure 7. Answers to the question 7 


\section{What type of techniques do you prefer while looking over and mastering the method of theorem-proof?}

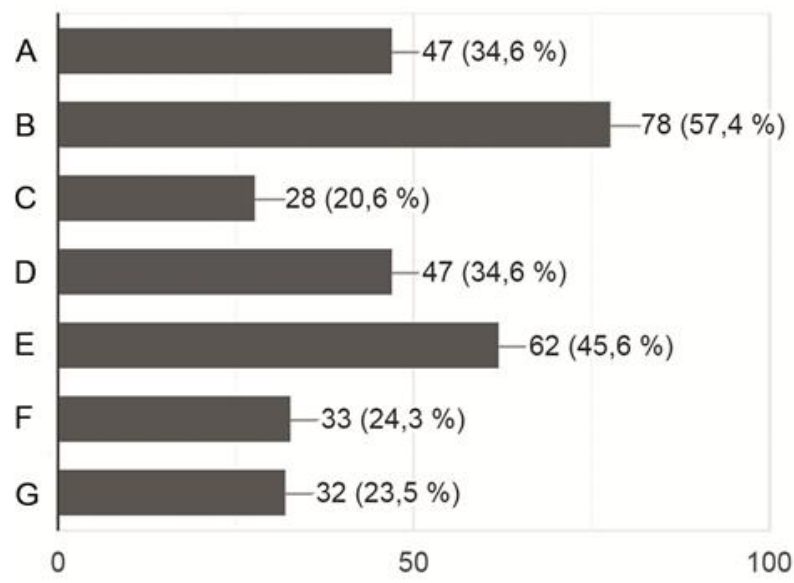

A I offer students to reproduce (orally or in pen) the theorem-proof;

B I offer students to distinguish the main idea or plan of the proof;

C I offer students give an argument to each stage of the proof;

D I offer students to fill in the gaps in the given variant of the theorem-proof where argumentation or some steps of the proof are missed;

E I offer students to give the list of the main notions, axioms, previously proved theorems used in the theorem-proof;

F I offer students to comment on some drawings that demonstrate every step in theorem-proof separately and to make appropriate conclusions;

G I offer students to supplement the drawing to make the stages of theorem-proof clear.

Figure 9. Answers to the question 9

\section{Factor Analysis}

Factor Analysis was used to identify the explicit and hidden factors that influence the effectiveness of the teacher's techniques of teaching the proof of the theorems into the educational process.

The factor analysis included such steps:

1) calculating the correlation matrix for input variables;

2) principal component analysis (selecting the principal factors using the extraction method);

3) identification of the simplified factors' structure using a rotation method (Varimax with Kaiser Normalization);

4) interpretation of the newly obtained factors as integral variables.

The numerical value obtained (0.576) of the Kaiser-Meyer-Olkin sampling adequacy demonstrates a sufficient sample correlation for the factor analysis.

The Bartlett spherical criterion indicated a statistically significant result since correlations between variables differed significantly from zero (Table 1). Table 2 lists the names of variables and grouping results (community).

Table 1. A measure of sampling adequacy and Bartlett's criterion

\begin{tabular}{|c|c|c|}
\hline \multicolumn{2}{|c|}{ Kaiser-Meyer-Olkin measure of sampling adequacy } & 0.576 \\
\hline \multirow{3}{*}{ Bartlett's test of sphericity } & Approx. Chi-Square & 253.239 \\
\cline { 2 - 3 } & $\mathrm{df}$ & 91 \\
\cline { 2 - 3 } & $\mathrm{Sig}$ & 0.000 \\
\hline
\end{tabular}

Table 2. Variables and grouping results (community)

\begin{tabular}{|c|c|c|c|}
\hline № & Names of variables & Input & Output \\
\hline $\mathrm{V}_{1}$ & Teacher's work with students of different classes (K7-K11) & 1.000 & 0.734 \\
\hline $\mathrm{V}_{2}$ & Teacher's work experience & 1.000 & 0.715 \\
\hline $\mathrm{V}_{3}$ & Teacher's positive attitude towards the importance and the need to teach students to prove theorems & 1.000 & 0.657 \\
\hline $\mathrm{V}_{4}$ & $\begin{array}{l}\text { A wide range in teacher's positive beliefs about the importance and the need to teach students to prove } \\
\text { theorems }\end{array}$ & 1.000 & 0.491 \\
\hline $\mathrm{V}_{5}$ & Dominant way of the collaboration of a teacher and students on theorem proof & 1.000 & 0.520 \\
\hline $\mathrm{V}_{6}$ & Quantitative variety of techniques used by a teacher to organize collaboration with students on theorem proof & 1.000 & 0.592 \\
\hline $\mathrm{V}_{7}$ & Collaboration of a teacher and students in reviewing and mastering the method of theorem proof & 1.000 & 0.648 \\
\hline $\mathrm{V}_{8}$ & Quantitative variety of techniques used by a teacher to review and master the method of theorem proof & 1.000 & 0.600 \\
\hline $\mathrm{V}_{9}$ & Collaboration of a teacher and students in establishing connection types in the chains of reasoning & 1.000 & 0.591 \\
\hline $\mathrm{V}_{10}$ & $\begin{array}{l}\text { Quantitative variety of traditional educational methods used by a teacher in teaching students to prove the } \\
\text { theorems }\end{array}$ & 1.000 & 0.534 \\
\hline $\mathrm{V}_{11}$ & Quantitative variety of educational means used by a teacher in teaching students to prove the theorems & 1.000 & 0.518 \\
\hline $\mathrm{V}_{12}$ & Quantitative variety of the sign-symbolic covering of theorem proof in textbooks & 1.000 & 0.617 \\
\hline $\mathrm{V}_{13}$ & Existence of difficulties that students have while performing theorem proof & 1.000 & 0.462 \\
\hline $\mathrm{V}_{14}$ & Quantitative variety of difficulties students have while performing theorem proof & 1.000 & 0.264 \\
\hline
\end{tabular}


Table 3 shows the characteristics of separate factors: the number, the sum of the squared loading, the percentage of the joint dispersion, which is caused by the factor, the corresponding cumulative percentage before and after loading.

Table 3. Total Variance Explained

\begin{tabular}{|c|c|c|c|c|c|c|c|c|c|}
\hline \multirow{2}{*}{$\begin{array}{c}\text { Componen } \\
t\end{array}$} & \multicolumn{3}{|c|}{ Initial Eigenvalues } & \multicolumn{3}{|c|}{ Sums of Squared Loadings } & \multicolumn{3}{|c|}{ Rotation Sums of Squared Loadings } \\
\hline & Total & $\begin{array}{c}\% \text { of } \\
\text { Variance }\end{array}$ & $\begin{array}{c}\text { Cumulative } \\
\%\end{array}$ & Total & $\begin{array}{c}\% \text { of } \\
\text { Variance }\end{array}$ & $\begin{array}{c}\text { Cumulative } \\
\%\end{array}$ & Total & $\begin{array}{c}\% \text { of } \\
\text { Variance }\end{array}$ & $\begin{array}{c}\text { Cumulative } \\
\% \\
\end{array}$ \\
\hline 1 & 2.442 & 17.444 & 17.444 & 2.442 & 17.444 & 17.444 & 2.185 & 15.604 & 15.604 \\
\hline 2 & 1.813 & 12.953 & 30.397 & 1.813 & 12.953 & 30.397 & 1.944 & 13.889 & 29.493 \\
\hline 3 & 1.418 & 10.130 & 40.527 & 1.418 & 10.130 & 40.527 & 1.351 & 9.652 & 39.145 \\
\hline 4 & 1.181 & 8.438 & 48.966 & 1.181 & 8.438 & 48.966 & 1.338 & 9.555 & 48.699 \\
\hline 5 & 1.087 & 7.764 & 56.730 & 1.087 & 7.764 & 56.730 & 1.124 & 8.031 & 56.730 \\
\hline 6 & .991 & 7.078 & 63.808 & & & & & & \\
\hline 7 & .934 & 6.669 & 70.477 & & & & & & \\
\hline 8 & .804 & 5.744 & 76.221 & & & & & & \\
\hline 9 & .762 & 5.445 & 81.666 & & & & & & \\
\hline 10 & .678 & 4.845 & 86.511 & & & & & & \\
\hline 11 & .598 & 4.268 & 90.779 & & & & & & \\
\hline 12 & .531 & 3.794 & 94.573 & & & & & & \\
\hline 13 & .405 & 2.894 & 97.467 & & & & & & \\
\hline 14 & .355 & 2.533 & 100.000 & & & & & & \\
\hline
\end{tabular}

Figure 10 presents an Eigenvalue graph that illustrates five selected factors before loading.

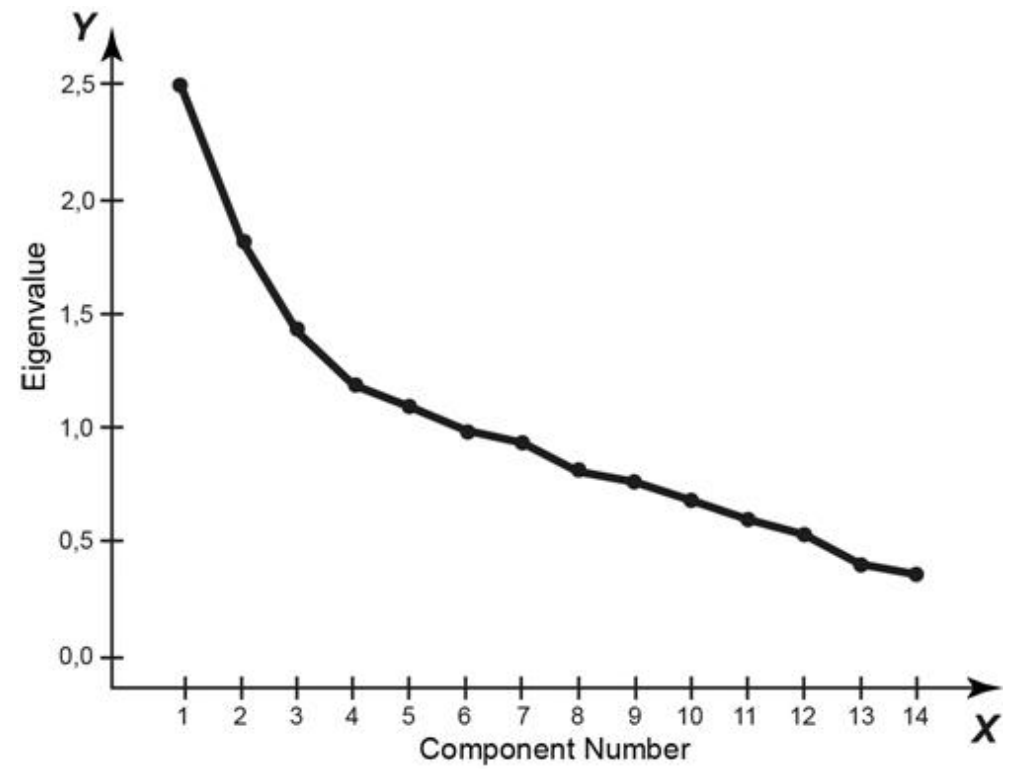

Figure 10. Initial Eigenvalues 
Table 4. Rotated Component Matrix

\begin{tabular}{|c|c|c|c|c|c|c|}
\hline \multirow{2}{*}{ № } & \multirow{2}{*}{ Names of variables } & \multicolumn{5}{|c|}{ Components } \\
\hline & & 1 & 2 & 3 & 4 & 5 \\
\hline $\mathrm{V}_{1}$ & Teacher's work with students of different classes (K7-K11) & & & & & 0.837 \\
\hline $\mathrm{V}_{2}$ & Teacher's work experience & & & -0.787 & & \\
\hline $\mathrm{V}_{3}$ & $\begin{array}{l}\text { Teacher's positive attitude towards the importance and the need to } \\
\text { teach students to prove theorems }\end{array}$ & 0.468 & & & 0.644 & \\
\hline $\mathrm{V}_{4}$ & $\begin{array}{l}\text { A wide range in teacher's positive beliefs about the importance and the } \\
\text { need to teach students to prove theorems }\end{array}$ & & 0.661 & & & \\
\hline $\mathrm{V}_{5}$ & $\begin{array}{l}\text { Dominant way of the collaboration of a teacher and students on } \\
\text { theorem proof }\end{array}$ & 0.462 & & & & \\
\hline $\mathrm{V}_{6}$ & $\begin{array}{l}\text { Quantitative variety of techniques used by a teacher to organize } \\
\text { collaboration with students on theorem proof }\end{array}$ & & 0.735 & & & \\
\hline $\mathrm{V}_{7}$ & $\begin{array}{l}\text { Collaboration of a teacher and students in reviewing and mastering the } \\
\text { method of theorem proof }\end{array}$ & 0.785 & & & & \\
\hline $\mathrm{V}_{8}$ & $\begin{array}{l}\text { Quantitative variety of techniques used by a teacher to review and } \\
\text { master the method of theorem proof }\end{array}$ & & 0.698 & & & \\
\hline $\mathrm{V}_{9}$ & $\begin{array}{l}\text { Collaboration of a teacher and students in establishing connection } \\
\text { types in the chains of reasoning }\end{array}$ & 0.694 & & & & \\
\hline $\mathrm{V}_{10}$ & $\begin{array}{l}\text { Quantitative variety of traditional educational methods used by a } \\
\text { teacher in teaching students to prove the theorems }\end{array}$ & & -0.705 & & & \\
\hline $\mathrm{V}_{11}$ & $\begin{array}{l}\text { Quantitative variety of educational means used by a teacher in teaching } \\
\text { students to prove the theorems }\end{array}$ & -0.484 & & 0.426 & & \\
\hline $\mathrm{V}_{12}$ & $\begin{array}{l}\text { Quantitative variety of the sign-symbolic covering of theorem proof in } \\
\text { textbooks }\end{array}$ & & & & 0.764 & \\
\hline $\mathrm{V}_{13}$ & $\begin{array}{l}\text { Existence of difficulties that students have while performing theorem } \\
\text { proof }\end{array}$ & & & 0.614 & & \\
\hline $\mathrm{V}_{14}$ & $\begin{array}{l}\text { Quantitative variety of difficulties students have while performing } \\
\text { theorem proof }\end{array}$ & & & & & \\
\hline
\end{tabular}

Table 4 shows the factor loadings matrix after loading.

\section{Discussion}

The results obtained allowed us to distinguish five factors that influence the cooperation of teachers and students at the stage when a teacher presents reasoning and proving, organizes students to review and master the proof.

Factor 1 combines the following variables: teacher's positive attitude towards the importance and need to teach students to prove theorems $\left(\mathrm{V}_{3}\right)$, the dominant way of collaboration of teacher and students on theorem proof $\left(V_{5}\right)$, a collaboration of a teacher and students in reviewing and mastering the method of theorem proof $\left(\mathrm{V}_{7}\right)$, a collaboration of a teacher and students in establishing connection types in the chains of reasoning $\left(\mathrm{V}_{9}\right)$. A quantitative variety of educational means used by a teacher in teaching students to prove the theorems $\left(\mathrm{V}_{11}\right)$ has a negative loading on the factor. This factor was named the realization of the invariant core of working with the theorem proof. It should be noted that by analogy to the factors distinguished in mastering the wording of the theorem [24], any 'variance' in the traditional methodological procedure used to work with the theorem proof in factor 1 is not reflected. So, we use the term 'invariant core'. The variability is reflected in other factors.

It should be noted that variables of "Collaboration of a teacher and students in reviewing and mastering the method of the theorem proof" $(0.785)$ and "Collaboration of a teacher and students in establishing connection types in the chains of reasoning" $(0.694)$ have the highest load. The efficiency of the work with the proof of a theorem can be improved due to the increased attention of teachers to this fact. Variable "Quantitative variety of educational means that teacher use in teaching students to prove the theorems" $\left(\mathrm{V}_{11}\right)$ has negative load on this factor. Therefore, realizing the invariant core of the work with the proof of a theorem, teachers use mostly one means of teaching being personally characteristic for them.

Factor 2 combines variables: a wide range in teacher's positive beliefs about the importance and the need to teach students the proof of the theorem $\left(\mathrm{V}_{4}\right)$; a quantitative variety of techniques used by the teacher to organize collaboration with students on theorem proof $\left(\mathrm{V}_{6}\right)$; a quantitative variety of techniques used by a teacher to review and master the method of the theorem proof $\left(\mathrm{V}_{8}\right)$. This factor describes variables that characterize discrete quantitative variance of a certain characteristic (polymorphism) in the traditional methodological procedure used to work with theorem proof. Summarizing all variables of a factor, we name it: polymorphism in the traditional methodological scheme of the work with the proof of a theorem. Since variable "Quantitative variety of 
traditional educational methods used by a teacher in teaching students to prove theorems" $\left(\mathrm{V}_{10}\right)$ has negative load on this factor, we can make a conclusion that using different ways of collaboration with students while proving theorems and mastering the proof, teachers realize one "favorable" traditional teaching method.

Factor 3 combines variables: an existence of difficulties that students have while proving a theorem $\left(\mathrm{V}_{13}\right)$, a quantitative variety of educational means used by a teacher in teaching students to prove theorems $\left(\mathrm{V}_{11}\right)$, teacher's work experience $\left(\mathrm{V}_{2}\right)$. This factor was named working experience factor.

Factor 4 combines variables: a quantitative variety of the sign-symbolic covering of the proofs of theorems in textbooks $\left(\mathrm{V}_{12}\right)$, teacher's positive attitude towards the importance and the need to teach students the proof of the theorem $\left(\mathrm{V}_{3}\right)$. This factor was named semiotic factor.

Factor 5 consists of one variable: teacher's work with students of different classes (K7-K11). This variable gave the name to this factor.

Additional analysis determines whether there is a correlation between the variable "Dominant way of the collaboration of a teacher and students on theorem proof" and students' difficulties occurring most often. The study shows that the situation when a teacher suggests an idea or a plan of the proof implemented by the students independently, is often implemented by such students' difficulties as conducting analysis of the theorem wording $\left(\chi^{2}=3.935, p<0.05\right)$. Namely, if a teacher focuses more attention on the idea of the proof, then the procedure of work with the wording of the theorem (selecting the explanatory part, hypothesis and conclusion) disappears from the focus of students' attention. At the same time, if a teacher works with the wording of the theorem, builds chains of conclusions in collaboration with students, then students have difficulties in the independent presentation of appropriate arguments to the individual steps in the proof $\left(\chi^{2}=3.987, p<0.05\right)$ most often. Besides, the study finds that if a teacher does not give a theorem proof in the ready-structured form but breaks it into a chain of the "isolated" assignments (each of them implements a separate step in the proof), then it is difficult for students to give possible consequences from certain foundations in the synthesized proof $\left(\chi^{2}=4.094, p<0.05\right)$.

The study also confirms that teachers find it necessary to teach students to prove theorems. We should mention, that this opinion of teachers does not depend on the number of classes where he/she teaches Geometry $\left(\chi^{2}=\right.$ $=13.376, p>0.05)$ and on his/her work experience at $\operatorname{school}\left(\chi^{2}=15.571, p>0.05\right)$.

\section{Conclusions and Prospects of Further Research}

Thus, the conducted research shows that there are significant gaps and shortcomings in the practice of teaching a theorem proof in secondary school. Although teachers realize the importance of teaching students to prove mathematical facts, this work is conducted unsystematically.

Our research shows that the overwhelming majority of teachers prefers to consider the proofs for some theorems in the classroom and offers students to learn other theorems independently at home. This practice is quite justified for the stages of didactic cycle implementation. However, this organization form of learning theorems complicates teacher's control of the process and the results of learning and proving those theorems designed for students' independent learning. This work requires additional organizational efforts of a teacher (control, check, and analysis). Neglecting it leads to the fact that students generally refuse to prove theorems independently, considering this work to be too difficult and useless for them. In particular, these trends are actualized in the context of the fact that independent mastering of educational and cognitive activity for students is quite problematic.

The research confirms that the vast majority of teachers organize students' work with the theorem proof under the guidance of a teacher; fewer respondents organize students' independent work. Some teachers try to provide the dosed assistance to their students (in the form of a plan, the idea of proving, other heuristic tips that the students subsequently implement independently). However, none of the ways of organizing teacher-student interaction in the process of teaching a theorem proofs does not deprive students of difficulties.

The indicative fact is that teachers are not sufficiently aware of how to implement a problem approach in teaching the proof of a theorem, how to combine a chain of subproblems, each of which takes a separate step in the proof, and later to synthesize independent proof of a theorem.

We would like to stress that the potential of the research-based method is not used sufficiently in teaching students to prove a theorem.

The important factors determining the time efficiency when a teacher organizes teaching and learning of a theorem proof include: 1) the realization of the invariant core of working on the proof of a theorem; 2) polymorphism in the traditional methodological scheme of the work with the proof of a theorem; 3) teacher's work experience factor; 4) semiotic factor; 5) teacher's work with students of different classes (K7-K11). Analysis of the factors and numerical loadings of the variables that form them allow us to draw some conclusions.

First, the study confirms that collaboration of a teacher and students in reviewing and mastering the method of a theorem proof, and in establishing connection types in the chains of reasoning have the highest load in the realization of the invariant core of working on the proof of a theorem. 
The efficiency of work on proving a theorem can be improved due to the increased attention of teachers to these kinds of students' activities. Second, a variety of means used by teachers in teaching to prove a theorem and students' difficulties in mastering the way of proving do not depend on teacher's experience. It means that both the experienced teachers and their young colleagues face the students' difficulties in proving theorems. Our research also finds the tendency that both the experienced teachers and their young colleagues diversify the process of teaching Mathematics involving the latest learning means in the educational process.

The influence of semiotic factor being found shows that the presentation of theorems in textbooks for different levels of teaching Mathematics should be different. It is better to present the proof in the textbook in the structured way, in separate steps for the students who study Mathematics in depth. We recommend to present the proof of a theorem in the textbook in the form of a sequential presentation (the text reproduces the sequence of reasoning) for the students who do not study Mathematics in depth.

Significant difficulties of students in mastering the methods of consistent proof reasoning form the problem field for further research. In particular, the problem of mastering general methodical and heuristic schemes, individual methods and techniques, forms and means of searching the way of proving a theorem is actualized.

\section{REFERENCES}

[1] Ball, D. L., Hoyles, C., Jahnke, H. N, \& Movshovitz-Hadar, N. (2002). The Teaching of Proof, ICM 2002, Vol. III, 907-920. Retrieved from http://www.mathunion.org/ICM/ /ICM2002.3/Main/icm2002.3.0907.0920.ocr.pdf

[2] Van Hiele, Pierre (1985) [1959], The Child's Thought and Geometry, Brooklyn, NY: City University of New York, pp. 243-252

[3] Ball, D. L., \& Bass, H. (2003). Making mathematics reasonable in school. In J. Kilpatrick, W. G. Martin, \& D. Schifter (Eds.) A Research Companion to principles and standards for school mathematics (pp. 27-44). Reston, VA: National Council of Teachers of Mathematics. Retrieved fromhttp://www.nctm.org/Handlers/AttachmentHandler.as $\mathrm{hx}$ ? attachmentID=VJwObEnErFo\%3d

[4] Franklin, J., \& Daoud, A. (2011). A Proof in Mathematics: an Introduction. Kew Books.

[5] Healy, L., \& Hoyles, C. (2000). From explaining to proving: a study of proof conceptions in algebra. Journal for Research in Mathematics Education, 31, 396-128.

[6] Marrades, R., Gutierrez, A. (2000). Proofs produced by secondary school students learning geometry in a dynamic computer environment. Educational Studies in Mathematics, 44, 87-125. Retrieved from http://citeseerx.ist.psu.edu/ /viewdoc/download?doi=10.1.1.541.8100\&rep=rep1\&type $=$ pdf

[7] Tarasenkova, N., Akulenko, I., Hnezdilova, K., \& Lovyanova, I. (2019). Challenges and Prospective Directions of Enhancing Teaching Mathematics Theorems in School. Universal Journal of Educational Research, 7(12): 2584-2596

[8] Tarasenkova, N. (2013). The quality of mathematical education in the context of Semiotics. American Journal of Educational Research, 1(11), 464-471. doi: 10.12691/ /education-1-11-2.

[9] Tarasenkova, N. (2014). Peculiar Features of Verbal Formulations in School Mathematics. Global Journal of Human-Social science: G: Linguistics \& Education, 14(3), 61-67. Retrieved from http://globaljournals.org/journals/ /human-social-science/g-linguistics-education

[10] Tarasenkova, N., \& Akulenko, I. (2014). The Problem of Forming and Developing Students' Logical Thinking in the Context of Subject Specialization in Secondary School. American Journal of Educational Research, 2(12-B), 33-40. doi: 10.12691/education-2-12B-7.

[11] Tarasenkova, N. (Eds). (2016). Conceptual framework for improving the mathematical training of young people: Monograph. In L. Kyba (A. Ed.). Budapest, Hungary: SCASPEE.

[12] Tarasenkova, N. (Eds). (2018). Current Status and Prospects of Mathematical Education: Monograph. In L. Kyba (A. Ed.). Budapest, Hungary: SCASPEE.

[13] Malek, A. \& Movshovitz-Hadar, N. (2011). The effect of using Transparent Pseudo-Proofs in Linear Algebra. Research in Mathematics Education, Vol. 13, No. 1, 33-58. Retrieved fromhttp://dx.doi.org/10.1080/14794802.2011.550719

[14] Movshovitz-Hadar, N. (1988). Stimulating presentations of theorems followed by responsive proofs. For the Learning of Mathematics, 8, No. 2, 12-30.

[15] Movshovitz-Hadar, N. \& Malek, A. (1998). Transparent Pseudo-Proofs - a bridge to formal proofs. In Proceedings of the International Conference on the Teaching of Mathematics, 221-223, New York: John Wiley \& Sons.

[16] Polya, G. (1981). Mathematical discovery: On understanding, learning and teaching problem-solving. New York: John Wiley \& Sons.

[17] Polya, G. (1954). Mathematics and plausible reasoning. Vol.1: Induction and analogy in mathematics. Princeton: Princeton University Press.

[18] Hanna, G. \& Jahnke, N. (2002). Another approach to proof. Zentralblatt für Didaktik der Mathematik, 34 (1), 1 - 8.

[19] Stylianides, A. J., \& Ball, D. L. (2008). Understanding and describing mathematical knowledge for teaching: Knowledge about the proof for engaging students in the activity of proving. Journal of Mathematics Teacher Education, 11(4), 307-332.

[20] Solow, D. (2002). How to read and do proofs: An introduction to mathematical thought processes. New York, NY: John Wiley \& Sons. 
[21] Senk, S. (1989). Van Hiele levels and achievement in writing geometry proofs. Journal for Research in Mathematics Education, 20(3), 309-321.

[22] Van Hiele, P. (1980) Levels of Thinking: How to Meet Them and How to Avoid Them. Paper presented at the Research Presession to the annual meeting of the National Council of Teachers of Mathematics, Seattle, WA.

[23] Hanna, G. \& Jahnke, N. (1993). Proof and application, Educational Studies in Mathematics, 24 (4), 421- 438.

[24] Shirikova, T. S. (2014). Methodology for teaching secondary school students the proofs of the geometry theorems using Geogebra. Arkhangelsk, Russia: Northern (Arctic) Federal University. [In Rus.].

[25] Hoyles, C., \& Noss, R. (1994). Dynamic geometry environments: What's the point? Mathematics Teacher, 87, 716-717.

[26] De Villiers, M. (1998). An alternative approach to proof in dynamic geometry, in R. Lehrer and D. Chazan (eds.), Designing Learning Environments for Developing Understanding of Geometry and Space, Lawrence Erlbaum, Mahwah (USA), pp. 369-393.

[27] De Villiers, M. (1999). Rethinking proof with the Geometer's Sketchpad, Key Curriculum Press, Emeryville, CA.hers College.

[28] Thompson, D. R. (1996). Learning and teaching indirect proof. Mathematics Teacher, 89(6), 474-482.

[29] Moore, R. C. (1994). Making the transition to formal proof. Educational Studies in Mathematics, 27(3), 249-266.

[30] Glass, G. V., \& Stanley, J. C. (1970). Statistical Methods In Education and Psychology. Englewood Cliffs, New Jersey 1 Prentice-Hall. 